\title{
OS SURPREENDENTES CAMINHOS DA ESTÉTICA: A POESIA MARGINAL DOS ANOS 70*
}

\author{
Teresa Cabañas \\ Universidade Federal de Santa Maria \\ tecama1@yahoo.com.br
}

\section{RESUMEN / RESUMO / ABSTRACT}

El presente trabajo intenta realizar una revisión de la poesía marginal brasileña surgida en los años setenta. Para eso, se la considera como una manifestación estética desajustada de los patrones poéticos modernos, con lo cual pasa aquí a proponerse la idea de que esta poesía habría modificado algunos de los parámetros tradicionales del quehacer poético, sobre todo a partir de la entrada en escena de nuevos agentes sociales y de sus modos sensibles diferenciados. Al mismo tiempo, se pone en discusión la pertinencia de algunos principios críticos utilizados para su interpretación y valoración por parte de la crítica académica.

PALABRAS ClAVE: poesía marginal, inestabilidad estética, reapropiación estética.

O texto propõe uma revisão da poesia marginal brasileira, surgida nos anos 70. Considerada uma manifestação estética desajustada dos padrões poéticos modernos, propõe-se aqui a idéia de que esta poesia expressar o que se acredita seja uma modificação dos fundamentos tradicionais do fazer poético, sobretudo a partir da entrada em cena de novos agentes sociais e de seus modos sensiveis diferenciados. Ao mesmo tempo, coloca-se em discussão a pertinência de alguns princípios críticos utilizados para a sua interpretação e avaliação por parte da crítica acadêmica.

PaLAVRAS-CHAVE: Poesia marginal, instabilidade estética, reapropriação estética.

This article sets out to present a review of Brazilian marginal poetry that emerged in the 1970 s. To do so, it is considered as a maladjusted aesthetic manifestation of modern poetic patterns,

As idéias que aqui se apresentam estão desenvolvidas no livro Cabañas (2009). 
with which the idea is proposed that this poetry may have modified some of the traditional foundations of poetic production, particularly since the emergence of new social actors and their different sensitive ways. At the same time, this article discusses the relevance of certain critical principles that are used by academic criticism for their interpretation and evaluation.

KEYWORDS: marginal poetry, aesthetic instability, aesthetic re-appropriation.

\section{A QUESTÃO TEÓRICA}

Não é de hoje o debate teórico que vem pondo em discussão a conveniência de formalizar bases hermenêuticas que permitam uma percepção mais apropriada do sentido -tanto estético como social- de certos fenômenos culturais que nas últimas décadas nos assombram com seus desdobramentos inusitados. Se a pauta não é nova, já que se inicia no alvorecer do espanto crítico pós-moderno, isso não garante que, com o correr do tempo, o assunto tenha sido superado, a ponto de pelo menos permitir-nos trafegar com mais tranqüilidade por alguns territórios literários que ainda hoje se mostram estranhos para certa parcela da crítica literária. No caso do Brasil, a situação aludida aparece em plenitude quando se repara no conjunto de propostas e manifestações poéticas que, arrancando na década de 50 com a poesia concreta e se estendendo até os anos setenta com a poesia marginal, dinamizaram a cena literária nacional com uma produção iconoclasta que alterou de raiz, e de modos diversos, a convivência com os parâmetros habituais do fazer poético. Sobre esse episódio, pode-se afirmar que tais experiências constituíram o último período de experimentação com formas estéticas surpreendentes e a última atualização literária de características grupais.

Em relação à poesia marginal, tema que me proponho abordar nestas páginas, a necessidade de novos paradigmas de interpretação se explicita de maneira cruenta não só pelo desmantelamento de alguns dos princípios básicos da poesia moderna visível na proposta, como também porque o "desatino da rapaziada" desvelou o caráter conservador e elitista de um importante e representativo setor da crítica acadêmica, que de imediato foilhe apontando uma natureza comprometida com o rebaixamento da "essência poética" e com os imperativos mercadológicos bestificadores de mentes e espíritos. Uma "barbárie poética", segundo um conhecido artigo a circular na década de oitenta (Dantas 42). Na verdade, poucos foram os que à época, e nos anos que se seguiram, atinaram a observar na avalanche de poemas, publicações e performances do movimento modos estéticos que denunciavam 
a existência de formas sensíveis próprias de uma determinada coletividade social, procedente de um lugar cultural considerado de pouco atrativo e transcendência: o âmbito da vivência juvenil, da existência homossexual, da opacidade do mundo cotidiano e doméstico ${ }^{1}$. Formas contraculturais cuja expressão se declarava muito pouco predisposta a se identificar com modelos de escritura acadêmicos, mesmo quando forçosamente com eles dialogassem para promover em benefício próprio uma visibilidade social e cultural cujos promotores consideravam pertinente ${ }^{2}$.

Assim, revisitar este momento de agitação cultural demandaria ainda hoje um exercício não apenas historiográfico, mas de disposição para encarar suas desajustadas formas poéticas como maneiras estéticas diferenciadas, sem negligenciar, por outro lado, o funcionamento do mecanismo de legitimação crítica que naquele momento se posicionou a respeito da natureza destas expressões. Isso porque são esses conteúdos os que ainda resultam exemplares para orientar qualquer exercício crítico que na atualidade se ocupe das formas tão diversas do fazer estético no mundo globalizado. As páginas que seguem se orientam por essa motivação.

\section{O IMPASSE}

A década de 50 tornou visível no Brasil o esgotamento a que chegaram as formas consagradas do fazer poético ${ }^{3}$; revelou, mais precisamente, as limitações

\footnotetext{
Heloisa Buarque de Hollanda é talvez o nome mais importante nesse sentido, pela prontidão com a qual já na década de setenta se posiciona perante a nova poesia através de uma reflexão cheia de possibilidades instigantes. Haveria que lembrar também a pesquisa que no campo da antropologia cultural desenvolve Carlos A. Messeder Pereira (1981), publicada sob o título de Retrato de época. No mesmo ano aparecem as interessantes colocações de Glauco Mattoso no pequeno livro $O$ que é poesia marginal?

A denominação de poesia marginal abrange, na verdade, uma faixa bastante ampla e variada de escrituras poéticas, que se fizeram acompanhar de uma série de práticas e ações inéditas, como as que incidem no circuito de edição e circulação das obras. Estas eram impressas em mimeógrafo, pelo qual o movimento também ficou conhecido como "geração mimeógrafo", e vendidas pelo próprio poeta em lugares públicos, como bares, cafés ou nas filas de cinema.

Correndo o risco da generalização, pode-se dizer que funcionam à época dois registros estabelecidos: o que se gesta à sombra das vanguardas de 22 com sua aproximação a temas da vida cotidiana ou da cultura popular e de tonalidade coloquial, e o que, opondo-se
} 
desse modelo à hora de articular alternativas que possibilitassem a expansão da comunicação poética. Em relação ao assunto, João Cabral de Melo Neto foi dos primeiros a apontar a inconveniente situação de incomunicabilidade na qual se debatia a produção poética no contexto nacional. Para ele, um tipo de poesia cujas formas se afastavam das necessidades e interesses do leitor, que para o poeta pernambucano não era outro senão o homem médio, habitante das cidades.

A sua conferência "Da função moderna da poesia" -pronunciada por Cabral (97) no Congresso Internacional de Escritores, realizado em 1954, em São Paulo- é principalmente um chamado de alerta que toca na ferida aberta pela modernidade no corpo da poesia; ferida impingida numa ação perversa porque ela constitui ao mesmo tempo o salvo-conduto para a permanência da poesia entre os homens: sua ruptura com a sociedade. Foi assim, pois, que a poesia, enredada nessa situação de dissimulada perversão, produto das condições da existência moderna, terminou por se distanciar dos homens para refugiar-se apenas, como o próprio Cabral sustentará, num "pequeno clube de confrades", cavando assim um fosso abissal entre ela e o leitor - este homem comum que sofre das condições limitadoras que a vida social moderna impõe para o cultivo das expressões do espírito. Entender esta já clássica circunstância da poesia moderna -seu afastamento do grande público- como uma "incapacidade" comunicativa do seu registro permite a Cabral tocar num aspecto que, se inédito para o momento, alcançará um desenvolvimento surpreendente nas décadas seguintes: a utilização de técnicas e modos vindos dos meios de comunicação como recursos para alargar o espectro da comunicabilidade das formas poéticas.

É a partir dessa última circunstância que não será mais possível deixar de notar o tenso diálogo a que a poesia tem-se forçado com eventos estruturais determinantes para a definição dos novos modos sensíveis no mundo contemporâneo. As formas que esse diálogo tem assumido acolhem uma diversidade de experiências emotivo-existenciais, veiculadas através de maneiras de expressão de cunho variadíssimo. É na multiplicidade da sua formalização que se poderá apreciar também o tipo de exigência que sobre a poesia se abate depois da Segunda Guerra, quando, na tentativa de acertar seu passo à marcha das vertiginosas mudanças empreendidas pela sociedade

a este, reintroduz o esteticismo subjetivo, temas elevados e uma prosódia correspondente, cuja referência principal é a chamada Geração de 45 . 
burguesa, o gênero deslizará para a configuração definitiva de um grave dilema. Aquele que mostrará numa das suas faces a dramática consciência que a poesia adquire de se saber enredada nos fios de uma curiosa cilada, vagarosamente articulada pela própria sociedade na qual ela precisa se manter ativa. Sendo essas formas poéticas em boa parte produto e reação à constante ameaça de restrição do seu espaço ativo -nos últimos tempos, por obra da eclosão e auge de novos padrões de sensibilidade vinculados ao desenvolvimento dos meios massivos de comunicação-, elas não poderiam deixar de registrar as evoluções de um processo que se descobre como a história da sua árdua luta pela sobrevivência. Querela com seu tempo histórico que permite ver nas diversas tentativas de novas linguagens a materialização da própria crise que a perpassa, quando meios, formas e valores em uso resultam insuficientes para representar as maneiras sensíveis de um determinado conjunto social.

Enfim, o espaço que acolhe a prática poética da contemporaneidade se desenha como um território submetido a terríveis tensões, as quais terminam por encerrar sua existência no que parece um beco sem saída: a polarização disjuntiva entre a recusa do valor comercial da obra - que, nas condições de produção impostas, decretaria seu fim -e o desejo de atualização, que, pelas mesmas condições, só parece alcançável mergulhando efetivamente na forma mentis do seu tempo. E esta última, como sabemos, definida cada vez mais pela efemeridade de gostos e sensibilidades, nos devolve à órbita das estratégias do consumo, alicerçada nas incessantes novidades técnicas e tecnológicas que movimentam o mercado. Acredito, então, que considerar esse conflito como a condição geral da produção poética moderna pode permitir-nos compreender mais ajuizadamente a atuação de manifestações mais recentes, sobretudo a daquelas que se percebem apanhadas numa realidade modelada pelo avanço das tecnologias de reprodução, dos meios de comunicação de massa e da indústria cultural.

Se esse é o contexto no qual se insere a poesia marginal e o mesmo que fará palpável no Brasil a crise dos paradigmas estéticos, no sentido dessa inadequação a que antes aludia, querer entender o significado de expressões tais nos obriga a perscrutar o próprio sentido da crise. Embora um primeiro encontro com a poesia marginal possa deixar a impressão de um rebaixamento dos códigos que tradicionalmente a poesia defendeu, na verdade nos colocamos perante uma tentativa consciente de trazer à tona modos $\mathrm{e}$ linguagens peculiares a certas vivências, consideradas pouco representativas do corpus estabelecido pela crítica literária institucional. Nos exemplos que me proponho abordar, o cotidiano e a sua linguagem se encontram exaltados 
com máxima contundência, de modo que o código poético se ergue sobre a precariedade de sistemas significativos cujos usos semânticos se caracterizam pela efemeridade, próprios da existência sensível de determinados grupos no espaço social urbano contemporâneo. Sistemas que na época eram olhados como estéreis para o tratamento poético. Algumas destas expressões se aproximam do seu tempo histórico sem o encantamento utópico ou o afã restaurador de outrora, para enfrentá-lo com grandes doses de ironia e humor e com o propósito deliberado de remeter-nos sem pudor para o mundo fosco do cotidiano urbano, do homem médio que o habita e da linguagem sem mistério que por aí circula, sem nenhuma aspiração a engrandecer-lhes as feições. Não apenas se trata aqui do tratamento temático do contexto existencial, como de uma tentativa de representá-lo formalmente, que começa pela imposição de uma palavra descaradamente prosaica, com o tom coloquial e o recorte balbuciante do mais trivial da expressão corriqueira. Vale a pena adiantar um exemplo desse ideário com este Coisas assim pardas, de Ângela Melin (Cit. em Campedelli 29), um quase manifesto do que se trata:

Canário da terra, marreco, chinfrim
coisas assim, nomes - Rita
coisas assim pardas, mestiças
de pequeno porte
coisas de fibra
embora com jeitos desvalidos
coisas pardas vivas
pulsantes
um poema assim.

Destarte, opto por encarar o que encontraremos no poema marginal como um desvio na ordem tradicional do sujeito que representa e que é representado, o que envolve tanto produtores como leitores, ambos se distanciando da figuração do padrão culto/letrado. Damos de cara, pois, com novos personagens entrando em cena ${ }^{4}$ e trazendo para a plateia do universo literário nacional discursos que o exercício hermenêutico acadêmico custa a assimilar, e que irá recusar por ver na sua constituição formas e jeitos que lhe parecem andrajos aviltantes substituindo as esplendorosas vestes urdidas pela poderosa tradição poética

$4 \quad$ Tomo de empréstimo a expressão do título do livro do sociólogo brasileiro Eder Sader, Quando novos personagens entraram em cena, no qual analisa as experiências e lutas dos trabalhadores da Grande São Paulo no decênio de 1970-1980. 
moderna. O traço polêmico se instala, então, ao redor de tais expressões, seja porque elas contestam padrões de sensibilidade estética instituídos pelo cânone, seja pela rejeição vinda de uma parte expressiva da crítica literária do momento. Como exemplo inicial da singular situação implantada por esta poética, fique o veredito de Alfredo Bosi. Como se verá, a questão dos modelos de interpretação e apreciação estética se faz aqui presente para desenhar a condição que na hora se colocava no âmbito dos estudos literários, e que irá pôr em discussão a pertinência dos princípios que constituem a vigência do cânone, na sua dimensão estética e crítica:

A gente fica até com um pouco de dificuldade de julgar esta poesia. Por todos nossos critérios, ela está aquém da linguagem poética. Por todos aqueles critérios, segundo os quais a poesia é uma representação, uma elaboração do fundo inconsciente ou imediato, esta poesia está apenas como uma, chame-mo-la assim, efusão. (...) Então, teríamos, dentro de uma concepção mais tradicional, até um pouco de escrúpulo em considerar isso como poesia (78).

Assim, o desbotamento que de fato se percebe nessas formas poéticas "desvalidas", quando não é sancionado pela crítica como descuido ou incapacidade -que os concretistas, por exemplo, vão chamar de "geléia geral"-, passa a ser visto como puro comodismo, com o qual simplesmente tais expressões se despacham para o universo do sub ou paraliterário mercadológico. Tal apreciação dá por encerrada a questão, deixando muitas vezes o caminho livre para que se as vincule ao projeto de alienação posto em marcha pelo próprio autoritarismo político da época (Martins) ou a uma visão "extremamente conservadora e autofágica", uma espécie de "antropofagia banguela" (Bonvicino 78) que apenas teria empobrecido as conquistas do Modernismo de 22.

Irrelevância, bobagem, esvaziamento são alguns dos (des)qualificativos através dos quais Vinícius Dantas (1986) também denuncia a nefasta situação de instabilidade estética que esses poetas teriam criado ao promover o que ele denomina de uma verdadeira "barbárie poética". Na mesma época, ele assinaria junto a Iumna Simon (1985) um artigo de título assustador, no qual a poesia marginal é definida, bem no impulso frankfurtiano, como a manifestação cultural que no Brasil teria promovido a definitiva adscrição à futilidade de uma sensibilidade estética que faria coincidir, até a sua indistinção, a banalidade do mundo com a banalidade do poema, num "samba do crioulo 
doido" 5 em que a poesia de tanto absorver os modos do cotidiano quase teria desaparecido afogada nas suas malhas. De modo que esse "pragmatismo comunicativo", como denominam esta prática poética, teria ocasionado uma "radicação natural e pouco exigente" da expressão poética "no cotidiano da sociedade de consumo".

De outra parte, é muito curioso que a questão da mudança no registro sensível promovida pela poesia marginal tenha sido vasculhada não por um crítico literário, mas por um antropólogo. Messeder Pereira (1981), valendose dos recursos da antropologia cultural, vai problematizar a tese do "vazio cultural", já bastante difundida no contexto intelectual da época. Assim, passa a entender a produção marginal não como mero fenômeno literário, mas como um fato cultural de dimensões mais amplas, o que lhe permite iluminar outra dimensão do movimento.

Se é verdade que a fixação de aspectos mais ideológicos conduz sua leitura a uma interpretação extraliterária daqueles conteúdos estéticos tidos como os mais representativos da poesia marginal, ou seja, seu antitecnicismo e antiintelectualismo, o que não desvenda a questão das formas estéticas, o trabalho aporta elementos de grande valia desde que comprova a gestação nesses anos de uma mudança comportamental ${ }^{6}$ e a formação de um tipo de sensibilidade diferenciada. Segundo postula o autor, à diferença da década anterior, que teria acolhido a discussão sistematizada de "grandes questões" sociais no interior das elites culturais e políticas, voltadas como estavam para a construção de uma alternativa de poder, a década de setenta registraria a ocorrência de um processo não sistematizado (em aparência, meio caótico) de fixação de "pequenos temas" e "pequenas coisas" como matéria do fazer poético. O que vem referendar a ideia de Heloísa Buarque de Hollanda (1981), segundo a qual estas poéticas estreantes estariam ocasionando um inédito processo de deslocamento da crítica social.

Priorizar tematicamente os assuntos desgastados da vida corriqueira de personagens anônimos e apresentá-los através de uma linguagem radicalmente coloquial e/ou pouco "literária" são as ações que para Messeder

A expressão alude a tudo aquilo que não tem nexo, é mirabolante, desordenado e sem sentido. Também é o título de uma paródia, bastante crítica, escrita por Stanislaw Ponte Preta, em 1968, para o Teatro de Revista e na qual ironiza a obrigatoriedade imposta às escolas de samba de só tratar temas históricos nos seus enredos.

Também mencionado por Mattoso (1981) e Miccolis (1987). 
Pereira sugerem uma prática comprometida com uma intensa "politização do cotidiano"7. Assim, o que para alguns críticos literários não passa de infantilização e desestabilização da poesia brasileira, para o antropólogo pode ser uma maneira de questionar o ranço intelectual que de há muito estaria distanciando a poesia do mundo real -isto é, dos seus leitores ${ }^{8}$. De forma tal que se poderia ver nessas expressões uma tentativa de arrancar o processo criativo da esfera exclusiva de grupos elitizados da cultura ilustrada, forçando a uma mais larga socialização do fazer literário.

Partindo, portanto, destas iniciais considerações, quero propor um roteiro de caminhos alternativos na intenção de alcançar uma compreensão diferenciada do desbotamento destes códigos discursivos. Para isso, se faz necessário indagar os mecanismos textuais, as táticas ou estratégias discursivas presentes em alguns destes poemas e que acredito serem vias para marcar a diferença e afirmar uma própria imago mundi, o que resulta então no desvelamento de uma(s) outra(s) sensibilidade(s), outra visão de mundo e outra poesia. Em outras palavras, me parece estar aí contida a luta por um espaço de expressão sensível que vem mostrar, por um lado, a procura do reconhecimento social de vivências socioculturais não integradas aos centros tradicionais do poder cultural, enquanto também oferece a oportunidade de observar o comportamento de uma prática crítica que lhes nega legitimidade estética.

\footnotetext{
As características até agora assinaladas foram interpretadas como prova da alienação e neutralização ideológica que o establishment teria incutido no movimento. Nesse sentido a leitura de Messeder Pereira tem o mérito de mostrar como tais práticas veiculam uma maneira inédita de politização, isso no meio do chamado sufoco político vivido nesses anos no Brasil pela imposição da ditadura militar. Aliás, lembro aqui o caso de um desses poetas, Nicolas Behr, enquadrado no Ato Institucional Número 5 (AI5) que estabelecia uma série de restrições e penalidades para ações consideradas subversivas ou inconvenientes pela ditadura. O motivo no caso de Behr foram seus livrinhos mimeografados, acusados de pornográficos. Não que o fossem, mas a vigilância deve ter percebido, mais do que alguns setores da crítica literária do momento, algo subversivo neles, certamente a insurreição da linguagem e a quebra de antigas sutilezas discursivas.

A lembrança das teses apresentadas por João Cabral de Melo Neto, na conferência mencionada, é de novo oportuna. Há nelas um importante e pioneiro chamado de atenção para a grave problemática que se desenha entre a poesia e o leitor. Trato disto com mais detalhe em (2003).
} 


\section{A PROPOSTA: POÉTICAS DA INSTABILIDADE}

Como dissera em páginas precedentes, acredito que os modos estéticos trazidos pela poesia marginal estariam materializando uma luta pela conquista de espaços de expressão sensível próprios. É ao redor dessa idéia que gostaria de organizar, então, a proposta interpretativa que segue e para isso é necessário que nos localizemos no âmbito do possível imaginário que dá lugar ao tipo de representação simbólica que tais formas veiculam. Esse lugar mental de produção de sentido que é o imaginário materializa seu conteúdo em formas simbólicas que constituem diversos processos de representação, mecanismos que medeiam a relação entre a realidade e o seu "verdadeiro" significado. Este processo de representação está integrado tanto pela observação direta da realidade como pelos conteúdos imaginários que são produto dos desejos, expectativas e interesses latentes no plano consciente e inconsciente do sujeito social. Por isso, a representação se constitui como sistema intrincado de formas-conteúdos, principalmente porque no processo de compreensão da realidade, no qual também participa, a representação nos devolve a realidade de forma mediada e não direta. Por isso, a representação é criação simbólica, o que lhe permite colocar em questão os conteúdos de verdade estabelecidos por cada época e contexto social. Referida aos modos poéticos, a representação interessa, claro, como estrutura discursiva.

Como se sabe, um dos conteúdos codificados pelo discurso poético da modernidade é sua ânsia de universalidade, que se ancora nesse projeto totalizador que pretendia a unificação das experiências estéticas do sujeito ao redor de um conceito particular do belo, o que, como consequência, supõe a existência de uma única e centrada identidade para esse sujeito. É este imaginário da totalidade que deu à luz a série de formas simbólicas que hoje reconhecemos como características da representação estética moderna. Mas sendo o imaginário uma forma mentis histórica, ele está sujeito a sofrer alterações, como as que se fazem visíveis em muitos poemas marginais, nos quais se aprecia o abandono dos conteúdos do modelo totalizador (universalidade, eternidade, utopia, verdade, etc.) e sua substituição por um complexo de novos princípios que não apenas substituem aqueles conteúdos como os questionam.

Quando Nicolas Behr (25) declara em um dos seus poemas "Estou salvo: /a poesia não é tudo" ou Paulo Leminski (72), em letras garrafais, berra que "CHUTES DE POETA /NÃO LEVAM PERIGO À META" contradizem um dos fundamentos básicos da poesia moderna, que se acreditava "divina 
e misteriosa", como pensavam os românticos, ou capaz de infundir distinção à matéria mais humílima, como defenderam os movimentos modernistas de começo do século XX. A dessacralização desse conceito de poesia, que se faz ainda mais radical quando a figura do poeta naufraga junto -"Pobrás/ orgulhosamente apresenta/ um produto/ que vai pro lixo: /os poetas"-, implica no novo imaginário a aceitação de uma condição de deterioro e desaparecimento -"Iogurte com farinha: Leia antes que azede"" - que é simbolicamente a explicitação de sua não imortalidade, de sua efemeridade e não transcendência. A renúncia à grande obra ou, mais exatamente, ao modo como ela foi concebida pelo recorte da modernidade:

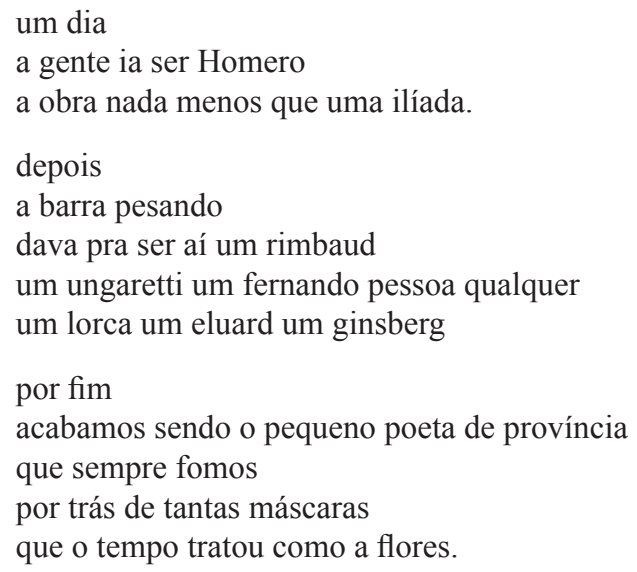

Este poema de Paulo Leminski (50) pode ser emblemático da nova situação que se coloca para o poeta, assim como da maneira de a ela responder. O poema, além de ser uma síntese da evolução da própria poesia e da maneira como, através da história, ela foi alterando os seus códigos, marca posição em relação à impossibilidade de seguir, no presente, operando com os mesmos princípios de representatividade que a caracterizaram e que pretenderam atingir uma comunidade "universal" pela voz de um sujeito "antena da raça". O fim das ilusões é aqui inegável, o recolhimento do sujeito à parcela do local também e o reconhecimento disso tudo explícito. Mas junto a isso está a reivindicação pelo particular, dada pelo uso de certas partículas idiomáticas 
de profunda coloquialidade ("a gente ia ser", "a barra pesando", "dava pra ser aí") atravessando o poema rumo a esse anti-intelectualismo mencionado. Contudo, perceba-se que não está ausente do poema o que poderia se chamar de tonalidade, uma atmosfera entre melancólica, derrotada e conformada que contorna a experiência existencial do eu lírico e que, mais do que a explícita declaração, é a que impõe o efeito reflexivo do poema.

Nos poucos exemplos até aqui citados é já possível reparar na operação de desarticulação do arcabouço poético tradicional que tanto espantou certos setores da crítica. Nestes textos não se trata apenas de uma vontade declarativa, mas, sobretudo, de uma ênfase formal, pois muitos desses poemas se organizam em estruturas rápidas e breves, de leitura (consumo) imediata -"Olha a passarinhada/ Onde?/ Passou" (Charles sp)-, que apelam para recursos retóricos de fácil assimilação, no intuito primeiro de efetivar a comunicação, mas cujos acenos de zombaria, por vezes só engraçada e outras profundamente irônica, veiculam a postura crítica. O emaranhado de consequências que daí advém é, sem dúvida, perturbador, pois envolve uma radical mudança de comportamento perante o fazer poético, que às vezes não hesita em abjurar de conquistas valiosas para a tradição moderna, como essa do poeta trabalhador da palavra e não mais sujeito da inspiração divina, Charles (sp):

Sou mais chegado ao escracho que ao desempenho mais chegado à música do que a porrada mais chegado ao vício do que a virtude sou pedestre sim senhor sou panfleta de uma sociedade anônima reconhecida entre os ares pesados da cidade.

Por outro lado, a poesia é aqui passageira, não mais eternizada pelo imaginário do poeta, que renega de si como ser escolhido ou superior para se reconhecer como mais um sujeito comum entre tantos -"Ah! sou um urbanoide circulando pela cidade", dirá Adauto num de seus poemas (Cit. em Hollanda 1998, 248). Disso procedem, então, certas apreensões como a de que a banalidade faz aqui sua festa para nivelar o registro poético "às mercadorias homogeneizadas e padronizadas pelo consumo" (Simon e Dantas 49).

Entretanto, o fato pode ser lido de outra maneira, talvez mais produtiva, que nos leve, por exemplo, a reparar nos intrincados mecanismos que estabelecem as relações que determinam o campo da produção simbólica como um espaço de disputa por um locus de expressão. Assim, o reconhecimento 
de que se partilha da engrenagem do consumo é também a confirmação do caráter histórico da produção cultural e de sua pertença a um contexto social específico, a sociedade burguesa. Mesmo perante a evidência inegável de que a literatura se realiza aí pela sua relação com o público consumidor, muitas vezes a crítica prefere, numa postura ingênua, desconhecer o fato em nome de uma transcendência impoluta, que além de negar as relações sociais de produção evidencia sua visão idealista e ilustrada, operando com idéias de notado fundo substancialista, mesmo quando crê estar pondo em prática princípios de ordem dialética.

Parece-me, então, que o gesto marginal em análise teria desnudado a hipocrisia desse ordenamento cultural que só se concebe ilustrado, e que se auto-proclama representativo da sociedade como um todo, dando-se o direito de banir tudo aquilo que nessa ordem não se adapte a sua visão. A prepotência de tal comportamento obstaculiza, entre outras coisas, o acesso à reflexão de desdobramentos dignos de consideração, como os que acompanham a necessidade implícita desta poesia captar um público leitor diferenciado daquele com o qual a visão acadêmica letrada se identifica. Por exemplo, não recusar o mercado e interessar-se por um leitor específico, que a visão elitista define equivocadamente como "uma platéia de adolescentes", revela alguns destes poetas como promotores de um curioso mecanismo de desmantelo da ideologia produtivista - aquele "sou mais chegado ao escracho que ao desempenho"- que a sociedade burguesa incute no ser social como um valor. Vejamos.

O caráter transitório, a não sublimidade que agora se admitem para a vida e a poesia -"O transcendental se dissolvendo/no efêmero"; "viver: verbo transitório e transitivo, transável conforme for" ${ }^{10}$ - permitem em muitos poemas reivindicar com força o caráter lúdico com o qual se passa a assumir o fazer poético, ao tempo que substitui a seriedade bem comportada da formulação ilustrada, com um acento maroto e divertido, como neste outro poema de Charles (Cit. em Hollanda 1982, 27):

bom é falar e jogar pelada um exercício contra a genialidade (espacinho) os mestres da vanguarda vem de complicar a gente vem de viver/ brincar e anotar 
Chamar a atenção para o espaço interestrófico usando o próprio termo denotativo ironiza os rigorosos princípios da matemática formal com a qual a racionalidade do poema concreto pensou a visualidade da poesia e projetou o seu fazer. Opera-se aqui uma dessublimação dos índices de complicação tradicionalmente ligados ao trabalho de criação poética, que agora passa a propositadamente lhe acentuar sua extrema inutilidade improdutiva, como nestes "Um homem sem profissão" e "Dilema do Ioga", de Cacaso (68 e 69):

Não sei se penso no futuro ou em que dedo do meu pé.

Já que estava à toa resolvi fazer um poema Agora faço pra ficar à toa.

O trabalho poético se reveste assim de uma gratuidade e ludicidade limítrofes com a própria ociosidade, de modo que sua confecção formal, para ser coerente com seus temas e enunciados, deve (a)parecer descuidada na sua cômoda brevidade, reduzida ao mínimo esforço de uma espontânea e nada polida coloquialidade. Tudo sintetizado neste antológico Leminski (39):

$$
\begin{aligned}
& \text { elas quando vêm } \\
& \text { elas quando vão } \\
& \text { versos que nem } \\
& \text { versos que não } \\
& \text { nem quero fazer } \\
& \text { se fazem por si } \\
& \text { como se em vão } \\
& \text { elas quando vão } \\
& \text { elas quando vêm } \\
& \text { poesia que sim } \\
& \text { parece que nem }
\end{aligned}
$$

Aos exemplos anotados se soma o livro que Cacaso publica em 1978. Com o sugestivo título de Na corda bamba, este conjunto de poemas será paradigmático em vários aspectos. Por um lado, o livro parece querer esfregar a gratuidade na cara do leitor e com tanta obstinação que, de repente, sua formalizada indolência explode como resposta e antídoto contra o clássico imperativo da sociedade burguesa segundo o qual "se deve ter uma existência produtiva". O poema (64) que dá título ao livro mostra na sua brevidade e na sua ênfase declarativa a prática abolição do trabalho de fazer poesia, quando quer esta confundida com a própria vida: 


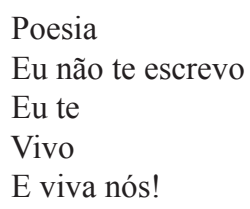

A declaração se torna radical e escandalosa porque propugna desterrar o mesmo registro utilizado para gravar o enunciado poético: a escrita, que, é bem verdade, o arranca do maleável e mutável espaço da oralidade, para resguardá-lo da intempérie e do desaparecimento. Mas é a escrita, ao mesmo tempo, a protagonista de uma longa história de imposição de hierarquias, que sempre penalizaram esse outro uso oral, popular e massivo. No paradoxo de não escrever poesia escrevendo-a parece, então, se manifestar o desejo imperioso de não perenizar a expressão através de uma forma que, quando assim a registra, pode petrificá-la e enclausurá-la nela própria, limitando, possivelmente, seu poder de penetração apenas a uns poucos.

Submergida na existência, a poesia poderia ganhar a mesma mobilidade desta, seja nos níveis da sua precariedade ou da sua grandeza, supondo-se assim uma vitalidade expressiva de alta rotatividade. Por isso, na extravagância da declaração, que corre por conta do paradoxo aludido, se potencializa, por um lado, um conceito humanizador, isto é, a poesia como um direito de todos e território ao qual todos podem concorrer; por outro lado, lateja o sonho de dinamizar a poesia através de uma forma proteica, ou seja, capaz de exercer sobre si própria tamanha capacidade de adaptação, transformação e modificação que não se descarta sua existência sob invólucros absolutamente inéditos e aparentemente impróprios - eu não te escrevo, eu te vivo. Poesia na "corda bamba", de equilíbrio precário e a ponto de não parecer tal.

A instabilidade de uma poesia na corda bamba pode-nos servir agora como elemento conceitual para propor um primeiro fechamento interpretativo. Situados como estamos no imaginário desta poesia, a vimos renunciar ao princípio de totalidade, o que significa, como dito, uma quebra de modelos que estaria sugerindo uma crise de paradigmas, tanto em relação aos padrões de escritura como ao conceito de sujeito que a expressa. A instabilidade é uma consequência disso, e ela vai dar feição a esta poesia em vários sentidos. Por um lado, seus conteúdos de efemeridade (rapidez, mobilidade, mutabilidade) iluminam a própria condição do tempo histórico-social no qual atua -“A vida é um adeuzinho", diz o Suspiro de Francisco Alvim-, assim como o burburinho desordenado e cambiante do cotidiano das ruas, a transitoriedade dos estados espirituais e psíquicos, a brevidade e intensidade das experiências, 
o "instantâneo revelado às pressas": "Te amo/ 24 horas/ por segundo", nessa Alta rotatividade de Nicolas Behr (74), e que leva a dois desses poetas a propor

um livro pra ler no ônibus, um livro entre dois cigarros, envelope de bilhetes inesperados, cadernos de notas, piadas, surpresas, indicações: o leitor o recebe como uma cola de colégio. Pode usá-lo pra conferir suas próprias respostas, ou rasgá-lo, se não estiver interessado na pergunta (Augusto e Vilhena).

De maneira que a instabilidade se molda como recurso formal extremo para tentar capturar numa representação o alucinante caráter mutável do seu tempo histórico. Neste Compondo de Chacal (sp) se aprecia a excitabilidade do sujeito que expressa sua não fixação, sua celeridade, a mesma que se transmite à forma do poema na falta de pontuação e no uso do enjambment que une os curtos versos numa tacada só que quase nos deixa sem fôlego:

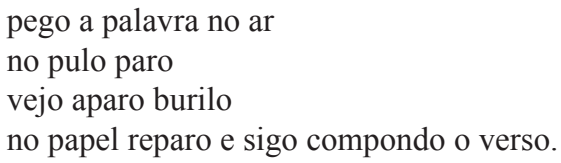

Mas, por outra parte, ela intervém também no plano temático para (d)enunciar a presença de um sujeito localizado em outras coordenadas sensíveis e em outro lugar social. Assim, um intenso sentimento de finitude se instala na experiência existencial desses sujeitos líricos despojados de uma referência duradoura na qual afirmar a vida, como nos exemplos a seguir:

demoliram minha infância

e eu desmoronei.

Bagaço, Behr

Parque de Diversões... Roda Gigante

Naquela cadeirinha vazia

Vai a minha infância.

Lyad de Almeida

sem futuro pela frente ou vivendo um futuro que já chegou:

vida feita de futuros

que não acontecem. $\quad$ Y. P. dos Santos

não chore meu amor não chore

que amanhã não será outro dia.

Cacaso 
Esta precariedade para manter e preservar elementos referenciais estáveis resulta típica da experiência emotiva instalada pelos mecanismos da reprodutibilidade técnica e tecnológica na sociedade tardo-moderna. Para o sujeito que se movimenta nessas coordenadas existenciais resulta então impossível se autorreconhecer nos princípios basilares que sustentaram o clássico ideário moderno da sociedade burguesa. Daí então que o reconhecimento do que se vive em todos os planos -existencial, político, social-seja a condição primeira a que este sujeito se obriga; por isso, muitas vezes a consciência do eu lírico desvela a inversão dos princípios que comandam a realidade material, como se vê nestes dois poemas quase irmãos, o primeiro de Leminski (80) e o outro de Roberto Schwarz (sp):
a vida varia
o que valia menos
passa a valer mais
quando desvaria.
o certo está torto
o torto está certo
o claro no bobo
o bobo no esperto.

É nesse contexto de desabamento que adquire relevância a declaração do eu lírico deste poema de Behr (71):
Deus está morto
Marx está morto
eu estou morto
vou enterrar os três
depois de amanhã.

e se entende a atitude de Orlando Tacapau, o debochado e transgressor protagonista de Preço da Passagem ${ }^{11}$, de Chacal (29), abjurando dos símbolos supremos da educação letrada que a representam:

11 Conta-se que o livro iria arrecadar fundos para a viagem a Londres que o poeta queria fazer por esses anos. Mimeografado, num formato de envelope, com trinta e uma folhas soltas, se fizeram mil exemplares que venderam pouco. 


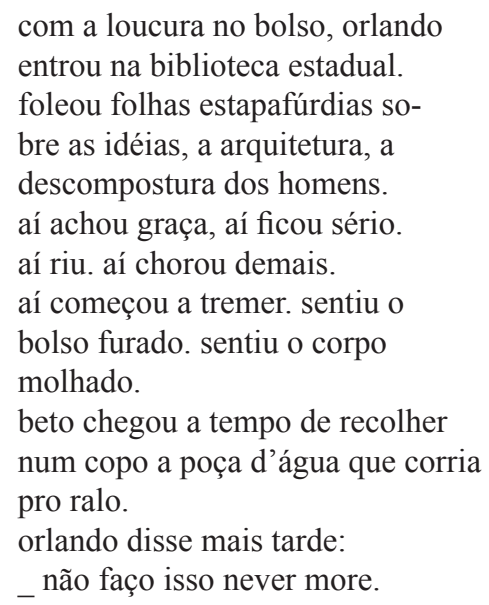

O que importa aqui não é a rejeição à biblioteca no plano da declaração temática, mas como essa rejeição se representa através de uns modos linguísticos que em si mesmos antagonizam com a norma usual daquele âmbito cultural. A coloquialidade ofensiva (foleou, aí, pro, never more) do registro oral contraria a reverência ilustrada e mostra a biblioteca como lugar de saber estagnado, enquanto a vitalidade corre solta no burburinho das ruas. Em outra ocasião e com a mesma linguagem despudorada, Tacapau foge da escola que o imobiliza ("sentado e estudantil") e onde só "manjava o absurdo e o rabo da professora". Assim, sem pensar duas vezes, nosso personagem "saiu de banda (...) pisou na escada e não apareceu mais por ali. pra quê?” (26). Prosaico em vários sentidos, o poema do qual se retiraram estes últimos versos tem um título para lá de sintomático: Não ato nem desato. Desarticulo. De modo que pegando a deixa, sintetizo nisso a visão e atitude desta poesia, que desajusta, desmonta, desmantela, desagrega elementos culturais e sistemas de percepção e sensibilidade tidos como eternos universais de representatividade geral.

Logicamente, tal desmoronamento de crenças, idéias e valores molda a constituição da identidade do sujeito. Como primeiro indício, em muitos exemplos da poesia marginal é evidente a tendência para a aceitação da insignificância e diminuição do eu lírico que aí se instala. Porém, isso se apresenta mediante a construção de um paradoxal mecanismo discursivo, que vai destacar de forma muito intensa a figura desse eu, a ponto de que a característica já foi vista como puro egotismo e pueril exaltação hedonista (Bonvicino 1984; Simon e Dantas 1985). Contudo, os elementos que 
gravitam ao redor dessa configuração originam derivações que complicam a unilateralidade do que se afirma, na medida em que esta poesia de "eus ciclópicos", como os chama Silviano Santiago (189), voluntariosa e vitalista, não poucas vezes deixa à mostra um tremendo achincalhamento do eu. Esse eu monitora sem constrangimento seu próprio processo desconstrutivo, que tanto se pode expressar de maneira descarnada, ácida, irônica ou engraçada, mas, em geral, sem grandes dramatismos, como nestes Cogito, de Torquato Neto (Cit. em Hollanda 1998, 64) e Self-portrait, de Salomão (34):

\author{
eu sou como eu sou \\ pronome \\ pessoal intransferível \\ do homem que iniciei \\ na medida do impossível \\ eu sou como eu sou \\ agora \\ sem grandes segredos dantes \\ sem novos segredos dentes \\ nesta hora \\ eu sou como eu sou \\ presente \\ desferrolhado indecente \\ feito um pedaço de mim \\ eu sou como eu sou \\ vidente \\ e vivo tranqüilamente \\ todas as horas do fim ${ }^{12}$.
}

Minha língua - mas qual mesmo minha língua, exal-

tada e iludida ou de reexame e corrompida?

- quer dizer: vou vivendo, bem ou mal, o fim

de minhas medidas; quer dizer: minha grande

paixão é um assunto sem valor; quer dizer:

meu tom de voz não fala mais grosso.

12 Waly Salomão (1983), nessa escrita gaguejante que é a parte final de "Na esfera da produção de si-mesmo", misto de monólogo e solilóquio, utiliza uma imagem quase idêntica à de Torquato quando diz: “... esta pessoa que está aqui falando na primeira pessoa eu do singular esta pessoa singular que sou eu pronome pessoal irredutível enquanto pronome... ". Em ambos os casos, o eu se desfaz tematicamente enquanto luta para se afirmar gramaticalmente. 
O sujeito se encolhe numa partícula gramatical, desmembrado de si mesmo, com uma vidência reduzida à lucidez necessária para aceitar-se e aceitar calmamente sua hora, sem buscar elevar-se em modelo de nada, apenas declarar sua experiência vivencial. Daí que o neorromantismo que Dantas (1986) crê ver por trás do que chama de "big ego" não pareça muito pertinente, condição que, na verdade, se desmancha no autorretrato de um sujeito irreconhecível na expressão embaralhada da repetição aleatória, com os timbres do cacoete da fórmula coloquial. Não há exaltação heroica ("POETA SEM/ LLAAUURREEAASS". Salomão 41), nem saudade ou melancolia pelo passado, nem mesmo memória para onde se evadir - pois, como diz o verso de J. Castañon Guimarães, "também a memória tem seus dias contados"-, nem projeção de um mundo ideal a ser alcançado no futuro, "Deus está morto". A ofuscante constatação do presente é o que resta para esses sujeitos, de maneira que eu diria ser essa percepção a que nos coloca na trilha dos seus modos sensíveis, a apreensão de um tempo e espaço descontínuos que impossibilitam a representação de uma imagem de totalidade e a construção de um eu centrado. Ele se equilibra na corda bamba, consciente de que pode cair a qualquer momento. A instabilidade molda agora a personalidade desse eu, que não raro se materializa na pele de qualquer anônimo rebaixado.

A instabilidade constrói, pois, a conflituosa densidade da subjetividade/ identidade marginal, que funde vitalidade e voluntarismo (que para alguns críticos é apenas puro desabafo), diminuição e rebaixamento. Ou seja, a instabilidade define a maneira como estes indivíduos vivem as coordenadas espaço-temporais específicas que lhes correspondem, condição irrecusável que reitera a impossibilidade de continuar atuando com os princípios da modernidade estética ${ }^{13}$. Poeta e poesia na corda bamba, poesia do risco, Cacaso (1974 sp):

\author{
Preciso \\ da palavra que me vista não \\ da memória do susto \\ mas da véspera do trapezista.
}

13 Para Cacaso (Brito 1982, 18), "a identidade está cindida, os valores (inclusive os estéticos) carecem de credibilidade, as relações são fugazes, o amor é enganoso, o presente é urgente, o futuro é sombrio". 
Parte fundamental dessa identidade estética em construção é constituída pelo registro linguístico de que faz uso. Bastante debatido pela crítica, o aspecto ainda é passível de exploração desde que parece apresentar brechas não muito notadas e através das quais podemos enxergar significados decisivos. A insistente coloquialidade de que se utiliza, e que para alguns não apresentaria inovação ou ruptura, pois no Brasil o coloquial já teria se esgotado como conquista do movimento modernista, vai, no entanto, se fazer extrema quando introduz tonalidades próprias da gíria. Isso significa a radicação da coloquialidade num setor mais restrito e específico: o da "galera" que inventa, usa e decifra seu código. Se Tacapau encarna o debochado transgressor, a gíria literalmente taca-pau ${ }^{14}$ na linguagem estabelecida, agredindo e desarticulando a estabilidade das boas maneiras linguísticas e comportamentais. Behr (14):
entro na sala
sem pedir licença
sem por favor
vou direto ao assunto
como vai?
tudo bem?
saio sem fechar a porta

Se a gíria é linguagem intimamente vinculada a um determinado grupo social, é claro que sua abrangência não poderia ser universal. Assim, seu alcance limitado pode tornar o poema rasgável, como concebem Augusto e Vilhena; isto é, nem representativo nem de interesse para todos. Já a mirada de antropólogo de Messeder Pereira (50) havia enxergado o poema marginal como "um conjunto de idéias e/ou práticas cotidianas (...) de certo ou certos grupos dentro da sociedade" (sublinhado meu), de modo que "o uso do palavrão" deveria ser encarado a partir desse contexto". Tempos antes, outro crítico expressara alarmado sua preocupação pelo perigo de uma tal linguagem ficar reduzida "a uma claque próxima, o que poderia estiolar a linguagem literária numa série de dialetos tribais" (Aguiar, sp.). Por sua parte, também anos oitenta, Buarque de Hollanda (94) observara como na poesia marginal se privilegiavam formas de "resistências setorizadas" que abandonariam "o

14 O uso da expressão "taca pau" introduz aqui uma dupla infração: a que aparece na própria natureza do seu uso coloquial meio tosco, e a que está no seu sentido semântico: bater, golpear. 
projeto globalizante de tomada de poder". Característica que, lembre-se, tempo depois passará a ser assumida pela critica internacional como um dos gestos associados à inclinação desconstrutiva do pós-moderno.

Circundando assim o aspecto, poderíamos perceber agora como o questionamento da linguagem que o uso da gíria faz está instalado no âmago estrutural do poema, resultando num recurso técnico para a obtenção de determinados efeitos importantes para a visão do grupo, com o que também se fragiliza a afirmação segundo a qual só haveria aqui a barbarização própria do puro desleixo. Esse recurso técnico, por comportar neste caso uma visão de mundo, é a evidência de que novos personagens, com suas visões culturais e sensibilidades sociais, abandonam os subterrâneos, para onde foram mandados pelo ordenamento cultural hegemônico, e entram em cena para mostrar sua existência com formas de fazer e dizer diferenciadas.

$\mathrm{O}$ dialeto quebra a prepotência moderna de uma única linguagem com poderes absolutos de representatividade universal. De maneira que essa "linguagem vira-lata" 15 (Santiago 1978a), traz consigo a descoberta dos particularismos reprimidos, diversidades culturais que a prática segregatícia e discriminatória da modernidade tantas vezes negou ${ }^{16}$. Além de constituir um dos principais detonadores da marginalidade literária desta poesia, acredito que o dialeto representa o espaço que se conquista e impõe para a expressão de interesses grupais específicos, sejam de tipo étnico, sexual, religioso, cultural ou estético. Desta perspectiva, o dialeto pode dar passagem à insurgência dos "particularismos humilhados" (Paz 202) ou apresentar a "multiplicação de Weltanschauungen" (Vattimo 13). Uma Babel que se rebela à autoridade e domesticidade de um só paradigma lingüístico. Babel papel, de Chacal (53):

e línguas como que babel

se rebelaram

e saíram de um bilhão de bocas.

15 "Vira lata" aplica-se ao cachorro sem pedigree e da rua.

16 Fenômeno que guarda interessantes coincidências com a poesia marginal é o caso da chamada lumpen poesia, manifestação, em vários sentidos mais radical, surgida no Uruguai na década de oitenta. Trigo (1994). 


\section{TÁTICAS DE REAPROPRIAÇÃO}

A definição da identidade marginal pode começar agora a ser esclarecida e redirecionada para um sentido conceitual que nos seja de utilidade. Embora o registro estético do "fim das ilusões" possa mostrar esse eu às vezes desiludido, quase sempre ele se reveste de um espírito de criatividade que pode ser proposto como tentativa de barganhar condições mais propícias para um sujeito em desvantagem. Por exemplo, o aceno pícaro através do qual o sujeito enterra Deus, Marx e ele próprio, introduz o aspecto como ressurgimento desse eu do bagaço, das sobras da existência, o que significa perscrutar o lugar social que ele ocupa como indivíduo subalterno (marginal). O sujeito desenvolve então modos peculiares para lidar, em surdina, com sua situação e principalmente enfrentar os mecanismos disciplinadores que lhe caem em cima. Daí que ele deva incentivar certas características, que se convertem em capacidades e habilidades, como as que aparecem na ficha de identidade de Orlando Tacapau:
maleabilidade em relação aos animais sem horários para as refeições alegre ardiloso instantâneo aé- reo pássaro instável su- jeito integral iluminações avulsas.

Flexibilidade e capacidade de adaptação que lhe permite ser isto e aquilo e ao mesmo tempo isto/aquilo: sujeito integral. Desta arte, a maleabilidade que lhe permite a Tacapau enfrentar as peripécias de sua viagem lhe impõe esse estado aéreo e instável, de forma que o jeito ardiloso depende da não fixação, do não centramento desse sujeito em alguma estrutura estável. A partir dessa instabilidade, dada pelo lugar de subalternidade (existencial e estética) de onde esse sujeito emerge, parece-me que se articula o que passo a chamar de "táticas de reapropriação". Com a nomenclatura busco chamar a atenção para o processo de exclusão, material e sensível, que envia esse sujeito e sua vivência para as margens da existência, e ao mesmo tempo destacar a atitude dinâmica que ele consegue articular a partir desse lugar. No que segue, passo a ver a instabilidade como a própria expressão do subalterno.

A opção de definir como sujeito subalterno o eu presente em muitos dos poemas marginais não se sujeita aqui de maneira estrita à procedência social 
dos autores reais destes textos. Mesmo que muitos deles se vinculem a uma classe média proletarizada, ou que alguns mantenham certo contato com a mídia, o que interessa é continuar no espaço de figuração do imaginário, que, como foi definido no começo, mostra através da representação simbólica, que reelabora desejos e frustrações, aspectos da realidade não evidentes nem imediatamente perceptíveis. A obtenção de uma leitura produtiva das questões estéticas não se dá, pois, pelo estabelecimento de um nexo direto entre condição social real e produção estética, mas penetrando as mediações que operam entre ambos os planos. Uma regra que nem sempre é considerada como se deveria. Falar de sujeito subalterno significa aqui haver topado com indícios estéticos que assim permitem defini-lo. Basta lembrar a sua condição existencial diminuída, a sua problemática relação com os ícones da cultura e da estética ilustradas, as formas linguísticas de que se vale e, não menos importante, a rejeição que provocou entre a crítica literária. O marginal está deslocado do centro, anda pelas beiradas (periferia), pelo subúrbio da linguagem e da estética. A condição marginal e subalterna significa, então, lidar com uma eterna desvantagem.

Como assegurar índices de sobrevivência em tal situação? Com táticas de reapropriação da subjetividade que se mostram como os modos ardilosos e sonsos de quem agem na moita. Táticas que são "engenhosidades do fraco para tirar partido do forte" (De Certeau 45), como ilustra a situação do eu lírico feminino deste poema de Leila Miccolis (Campedelli 70):

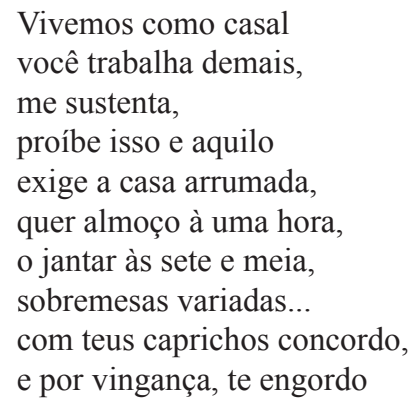

A forma de tentar essa reapropriação não é o tradicional confronto direto dos fatores que motivam a repressão. Pelo contrário. $\mathrm{O}$ eu agarra-se deles, para, na aparente concordância, criar um ardiloso mecanismo de revanche, que não dá nas vistas e passa despercebido. Numa outra versão, Carlos Saldanha/ Zuca Sardan (12) também preferirá a saída tangencial a apostar 
numa rebeldia contraproducente: "Uma opinião/ apoiada em baionetas/ degenera em bobagem/ se a gente deixar/a barriga na frente"; Leminski (77) reverterá os empecilhos da vida se apropriando deles: "não discuto/ com o destino/ o que pintar/ eu assino" -repare-se na letra cursiva como signo de personalização-e Cacaso (84), finalmente, descortina o modo malicioso de este agir: "eu sou manhoso eu sou brasileiro/ finjo que vou mas não vou". Tais modos se aproximam muito da pura descontração ou do simples gracejo sem transcendência, mas, são também as "mil maneiras de caça não autorizada" (De Certeau 38) mediante as quais os seres anônimos inventam o cotidiano e fogem dos sistemas de vigilância.

É a "arte do fraco" que, apoiada no agir tático, abre mão das estratégias ${ }^{17}$, pois, como vimos, não mais se atrela a projetos totalizantes de longo alcance. A tática é maleabilidade pura, e deve-se aproveitar das ocasiões para thes tirar algum proveito. Por isso é necessariamente instável, demanda sucessivas reacomodações, o que impõe ao sujeito um tipo de aprendizado que é abertura mental para a criatividade: se "É proibido pisar na grama/ o jeito é deitar e rolar" (Chacal 90), e "quem teve a mão decepada/ levante o dedo" (Behr 50). Não há, então, nestas expressões aceitação conformista da experiência diária, como alguns críticos entenderam, mas um jeito enviesado, tangencial, não frontal de driblar as agruras do cotidiano e que se justifica pela posição de desvantagem que se ocupa dentro do sistema. No plano do discurso, a saída vai recorrer muitas vezes à ironia, ao humor, à declaração ingênua, enquanto a composição estrutural do poema admite a paródia e o pastiche.

Sem espaço para detalhar estes últimos aspectos, que encaro como recursos condizentes com o universo sensível e com as condições existenciais específicas do sujeito que nestes poemas se constrói, recordemos que a eles se adjudicou a responsabilidade pela "desqualificação poética" e a "indigência do registro subjetivo", tal como Simon e Dantas (60) o apreciaram. Tendo olhado a manifestação a partir de outra perspectiva, parece-me, pelo contrário, que tais aspectos nos colocam de cara com esse tipo de criatividade "dispersa, tática, bricoladora" que De Certeau (41) identifica nas formas sub-reptícias assumidas pelos "grupos ou indivíduos presos nas redes da vigilância". Tretas e artimanhas discursivas que permitiram à poesia marginal emergir dos cafundós para colocar-se no espaço público da prática estética e fugir do poder centralizado e centralizador. 
A perspectiva crítica que até aqui se esboçou advém do diálogo com a desarticulação conceitual de certos paradigmas que a hermenêutica, enfrentada às alterações do tempo contemporâneo, vem realizando. A despeito do intenso e às vezes bizarro debate que a chamada pós-modernidade tem suscitado, e mesmo sem ter explicitado aqui suas questões mais pontuais, parece-me que esta condição sociocultural e estética funciona como espaço de existência cultural e como âmbito de elaboração ou retificação de recursos interpretativos a partir do qual inquirir a poesia marginal. À medida em que a situação tardo-moderna descobre a contradição básica da modernidade e enfraquece a supremacia dos conceitos absolutos, com todas as consequências que isso acarreta, nos oferece a condição inicial para reavaliar a prática estética de sujeitos culturais com interesses e modos de atuação diversos dos que a experiência moderna aceitou como modelares.

Assim nos será possível ver no descompromisso com a racionalidade do discurso letrado não a barbarização da estética, mas uma forma de mostrar como esse discurso é impositivo. Na sua ludicidade, gratuidade, zombaria e brincadeira não a desqualificação da capacidade crítica da poesia, mas recursos que lhe permitem implementar a "arte da dissimulação", maneiras ardilosas de enfrentar o poder hegemônico arbitrário e discriminador e se reapropriar de certos índices de autonomia ${ }^{18}$. No uso da gíria, não comodismo e desleixo, senão a diversidade linguística, a convocação da pluralidade que desarticula o discurso homogeneizador e mostra a existência do outro nas suas diferenças e particularidades. Na paródia e no pastiche, não a canibalização dos estilos, mas a não-dissolução das diferenças, o não-apagamento das oposições, o direito do outro se expressar por si.

Deve-se aceitar que a vocação estética da poesia marginal se realiza à luz de outra sensibilidade, que instaura uma illusio $^{19}$ que se revela como construção de um espaço estético-existencial diferenciado e inevitavelmente caracterizado como temporário e efêmero. A poesia marginal se materializa como experiência da diferença, e como tal desbarata a pretensão de constituir o belo absoluto, desmontando com seus modos peculiares as bases ideológicas do consenso estético da comunidade "universal". Assim, ela estaria indo ao

18 Segundo Marilena Chauí, "o desejo de práticas autônomas e diferenciadas, sem a tutelagem de organismos partidários, estatais ou empresariais" é traço inédito dos movimentos sociais surgidos nesses anos.

19 Bourdieu $(1990 ; 1996)$. 
encontro desse momento heterotópico que Vattimo (80) define como a "tomada de palavra por parte de múltiplos sistemas de reconhecimento comunitário, de múltiplas comunidades que se manifestam, se exprimem e se reconhecem em modelos formais e mitos diferentes".

A possibilidade de ainda contar com horizontes vitais para a realização existencial, nas constritoras condições tardo-modernas da periferia subdesenvolvida, só parece viável como experiência de pluralidade e consciência da existência de mundos plurais. A permanência da arte nessas condições coloca-se, então, como um árduo convívio com a instabilidade, como camaleônica capacidade para a transfiguração. Talvez por aí possamos reorientar o significado do desaparecimento da tendência como prática grupal e a diáspora de seus protagonistas, encaminhados às vezes para outros rumos, não como a inevitável consequência da ineficácia de seus métodos, da superficialidade de seus objetivos ou da irrelevância de suas formas estéticas, mas como encerramento de uma trajetória que tem muito de aprendizado, de um oportunismo tático que reconhece a necessidade da constante mobilidade, que pode considerar, se necessário, o próprio desaparecimento.

Por outro lado, aproximar-nos de manifestações como a poesia marginal enquanto membros da comunidade acadêmica que avalia e sanciona o universo da arte, supõe um inevitável diálogo com práticas que formalizam um conceito estético reticente às clássicas formulações do paradigma moderno. Por isso, desde que não procedamos a um confronto com nossos tradicionais canais de compreensão e avaliação, o entendimento das questões levantadas por movimentos como o aqui analisado continuará obscurecido pela pura negação discriminatória. Assim, então, o problema de epistemológico deriva numa questão ética, que nos exige um aprendizado que é constante e delicado exercício de aceitação e respeito pela diferença. E de reconhecimento de que nossas elaborações conceituais não são formalizações neutras, mas sim estruturas perpassadas pelos conteúdos ideológicos que, como sujeitos sociais, cada um de nós defende e representa.

\section{BIBLIOGRAFIA}

Aguiar, Flávio. "A literatura no retalho”. Jornal Movimento (12 de julho de 1976): sp.

Augusto, Eudoro e Bernardo Vilhena. "Consciência marginal". Arte em revista 8 (1984): 73. Bosi, Alfredo. "Debate sobre poesia". Rebate de pares 2 (1981): 15-22.

Behr, Nicolas. Restos Mortais. Brasília: Senado Federal, 1980.

Bonvicino, Régis. “A marginalidade circunstancial”. Arte em revista 8 (1984): 78. 
Bourdieu, Pierre. "El campo literario. Requisitos críticos y principios de método". Criterios 25-28 (Enero 1989-Diciembre 1990): 20-42. As regras da arte. São Paulo: Companhia Das Letras, 1996.

Brito, Antonio Carlos de. "Pindaíba de tatu". Leia Livros 51 (1982): sp.

Cabañas, Teresa. Que poesia é essa? Poesia marginal: sujeitos instáveis, estética desajustada. Goiânia: Ed. Universidade Federal de Goiás, 2009.

"Poéticas da comunicabilidade: Lugar de enunciação e modelos de interpretação". Revista de crítica literaria latinoamericana 57 (2003): 59-73.

Cabral de Melo Neto, João. "Da função moderna da poesia". Prosa. Rio de Janeiro: Nova Fronteira, 1998. 97-101.

Cacaso. Beijo na boca. São Paulo: Ed. Brasiliense, 1985.

Campedelli, Samira. Poesia marginal dos anos 70. São Paulo: Scipione, 1995.

Chacal. Drops de abril. São Paulo: Ed. Brasiliense, 1983.

Charles. Creme de lua. Rio de Janeiro: Estação Liberdade,1975.

Chauí, Marilena. "Notas sobre la crisis de la izquierda en Brasil". Nueva Sociedad 61 (1982): $35-42$.

Dantas, Vinicius. “A nova poesia brasileira e a poesia”. Novos Estudos 16 (1986): 40-53.

De Certeau, Michel. A invenção do cotidiano. Rio de Janeiro: Ed. Vozes, 1994.

Hollanda, Heloísa Buarque. 26 poetas hoje. 2a ed. Rio de Janeiro: Aeroplano Editora, 1998. Impressões de viagem. São Paulo: Brasiliense, 1981.

Hollanda, Heloísa Buarque de y C. A. Messeder Pereira. Poesia Jovem. São Paulo: AbrilEducação, 1982.

Leminski, Paulo. Caprichos e relaxos. São Paulo: Brasiliense, 1983.

Martins, Luciano. “A geração AI-5”. Ensaios de opinião. Rio de Janeiro: Paz e Terra, 1979: 62-67.

Mattoso, Glauco. O que é poesia marginal? São Paulo: Brasiliense, col. Primeiros Passos, 1981. Messeder Pereira, Antônio Carlos. Retrato de época. Rio de Janeiro: Editora Funarte, 1981. Miccolis, Leila. Do poder ao poder. Porto Alegre: Tchê!, 1987.

Paz, Octavio. Los hijos del limo. Barcelona: Seix Barral, 1974.

Salomão, Waly. Gigolô de Bibelôs. São Paulo: Brasiliense, 1983.

Santiago, Silviano. “O assassinato de Mallarmé”. Uma literatura nos trópicos. São Paulo: Ed. Perspectiva, 1978: 179-189.

"Um poeta novo: Geraldo Carneiro". José 10 (1978a): sp.

Sardan, Zuca. As de colete. Campinas, SP: Editora da Unicamp, 1994.

Simon, Iumna e Vinicius Dantas. "Poesia ruim, sociedade pior". Novos Estudos 12 (1985): 48-61.

Schwarz, Roberto. Corações veteranos. Rio de Janeiro: Ed. do autor, 1974.

Trigo, Abril. "Lumpen poesía y neomodernidad periférica: el caso uruguayo". Revista de crítica literaria latinoamericana 39 (1994): 247-266.

Vattimo, Gianni. A sociedade transparente. Lisboa: Eds. 70, 1991. 